\title{
Serum proteins differentially expressed in early- and late- onset preeclampsia assessed using iTRAQ proteomics and bioinformatics analyses
}

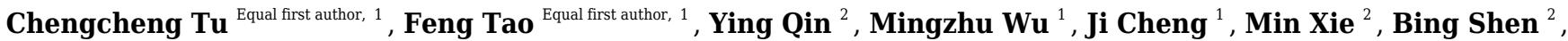 \\ Junjiao Ren ${ }^{3}$, Xiaohong Xu ${ }^{4}$, Dayan Huang ${ }^{3}$, Hongbo Chen ${ }^{\text {Corresp. } 1}$ \\ ${ }^{1}$ Department of Obstetrics and Gynecology, Maternal and Child Health Hospital Affiliated to Anhui Medical University, Hefei, Anhui, China \\ 2 School of Basic Medicine, Anhui Medical University, Hefei, Anhui, China \\ 3 Department of Science and Education, Maternal and Child Health Hospital Affiliated to Anhui Medical University, Hefei, Anhui, China \\ 4 Department of Clinical Laboratory, Maternal and Child Health Hospital Affiliated to Anhui Medical University, Hefei, Anhui, China \\ Corresponding Author: Hongbo Chen \\ Email address: chenhongbo@ahmu.edu.cn
}

Background. Preeclampsia remains a serious disorder that puts at risk the lives of perinatal mothers and infants worldwide. This study assessed potential pathogenic mechanisms underlying preeclampsia by investigating differentially expressed proteins (DEPs) in the serum of patients with early-onset preeclampsia (EOPE) and late-onset preeclampsia (LOPE) compared with healthy pregnant women.

Methods. Blood samples were collected from four women with EOPE, four women with LOPE, and eight women with normal pregnancies, with four women providing control samples for each preeclampsia group . Serum proteins were identified by isobaric tags for relative and absolute quantitation combined with liquid chromatography-tandem mass spectrometry. Serum proteins with differences in their levels compared with control groups of at least 1.2 fold-changes and that were also statistically significantly different between the groups at $P<0.05$ were further analyzed. Bioinformatics analyses, including gene ontology and Kyoto Encyclopedia of Genes and Genomes signaling pathway analyses, were used to determine the key proteins and signaling pathways associated with the development of PE and to determine those DEPs that differed between women with EOPE and those with LOPE. Key protein identified by mass spectrometry was verified by enzyme linked immunosorbent assay (ELISA).

Results. Compared with serum samples from healthy pregnant women, those from women with EOPE displayed 70 proteins that were differentially expressed with significance. Among them, 51 proteins were significantly upregulated and 19 proteins were significantly downregulated. In serum samples from women with LOPE, 24 DEPs were identified, with 10 proteins significantly upregulated and 14 proteins significantly downregulated compared with healthy pregnant women. Bioinformatics analyses indicated that DEPs in both the EOPE and LOPE groups were associated with abnormalities in the activation of the coagulation cascade and complement system as well as with lipid metabolism . In addition, 19 DEPs in the EOPE group were closely related to placental development or invasion of tumor cells.

Downregulationof pregnancy-specific beta-1-glycoprotein 9 (PSG9) in the LOPE group was confirmed by ELISA.

Conclusion. The pathogenesis of EOPE and LOPE appeared to be associated with coagulation cascade activation, lipid metabolism, and complement activation. However, the pathogenesis of EOPE also involved processes associated with greater placental injury. This study provided several new proteins in

Peer) reviewing PDF | (2019:11:43432:2:0:NEW 10 May 2020) 
the serum which may be valuable for clinical diagnosis of EOPE and LOPE, and offered potential mechanisms underpinning the development of these disorders. 
1 Serum Proteins Differentially Expressed in Early- and Late-Onset Preeclampsia Assessed

2 Using iTRAQ Proteomics and Bioinformatics Analyses

3

4 Chengcheng Tu${ }^{1, \#}$, Feng Tao ${ }^{1, \#}$, Ying Qin ${ }^{2}$, Mingzhu Wu${ }^{1}$, Ji Cheng ${ }^{1}$, Min $\mathrm{Xie}^{2}$, Bing Shen ${ }^{2}$,

5 Junjiao $\mathrm{Ren}^{3}$, Xiaohong $\mathrm{Xu}^{4}$, Dayan Huang ${ }^{3}$, Hongbo Chen ${ }^{1, *}$

6

$7 \quad{ }^{1}$ Department of Obstetrics and Gynecology, Maternal and Child Health Hospital Affiliated to

8 Anhui Medical University, Hefei, Anhui, China

$9{ }^{2}$ School of Basic Medicine, Anhui Medical University, Hefei, Anhui, China

${ }^{3}$ Department of Science and Education, Maternal and Child Health Hospital Affiliated to Anhui

11 Medical University, Hefei, Anhui, China

${ }^{4}$ Department of Clinical Laboratory, Maternal and Child Health Hospital Affiliated to Anhui

13 Medical University, Hefei, Anhui, China

\#Authors contributed equally in this work

$17 *$, Address correspondence:

18 Hongbo Chen, Ph.D., Department of Obstetrics and Gynecology, Maternal and Child Health

19 Hospital Affiliated to Anhui Medical University, 15 Yimin Road, Hefei, Anhui 230001, China, 20 Tel: +86-18056076983, Email address: chenhongbo@ahmu.edu.cn. 


\section{Abstract}

24 Background. Preeclampsia remains a serious disorder that puts at risk the lives of perinatal

25

mothers and infants worldwide. This study assessed potential pathogenic mechanisms underlying preeclampsia by investigating differentially expressed proteins (DEPs) in the serum of patients with early-onset preeclampsia (EOPE) and late-onset preeclampsia (LOPE) compared with healthy pregnant women.

Methods. Blood samples were collected from four women with EOPE, four women with LOPE, and eight women with normal pregnancies, with four women providing control samples for each preeclampsia group. Serum proteins were identified by isobaric tags for relative and absolute quantitation combined with liquid chromatography-tandem mass spectrometry. Serum proteins with differences in their levels compared with control groups of at least 1.2 fold-changes and that were also statistically significantly different between the groups at $P<0.05$ were further analyzed. Bioinformatics analyses, including gene ontology and Kyoto Encyclopedia of Genes and Genomes signaling pathway analyses, were used to determine the key proteins and signaling pathways associated with the development of PE and to determine those DEPs that differed between women with EOPE and those with LOPE. Key protein identified by mass spectrometry was verified by enzyme linked immunosorbent assay (ELISA).

Results. Compared with serum samples from healthy pregnant women, those from women with EOPE displayed 70 proteins that were differentially expressed with significance. Among them, 51 proteins were significantly upregulated and 19 proteins were significantly downregulated. In serum samples from women with LOPE, 24 DEPs were identified, with 10 proteins significantly upregulated and 14 proteins significantly downregulated compared with healthy pregnant women. Bioinformatics analyses indicated that DEPs in both the EOPE and LOPE groups were 
46 associated with abnormalities in the activation of the coagulation cascade and complement

47 system as well as with lipid metabolism. In addition, 19 DEPs in the EOPE group were closely

48 related to placental development or invasion of tumor cells. Downregulationof pregnancy-

49 specific beta-1-glycoprotein 9 (PSG9) in the LOPE group was confirmed by ELISA.

50 Conclusion. The pathogenesis of EOPE and LOPE appeared to be associated with coagulation

51 cascade activation, lipid metabolism, and complement activation. However, the pathogenesis of

52 EOPE also involved processes associated with greater placental injury. This study provided

53 several new proteins in the serum which may be valuable for clinical diagnosis of EOPE and

54 LOPE, and offered potential mechanisms underpinning the development of these disorders.

55

56 Keywords: preeclampsia, early-onset preeclampsia, late-onset preeclampsia, proteomics, LC-MS/MS, 57 iTRAQ 


\section{Introduction}

60 Preeclampsia (PE), a hypertensive disorder complicating pregnancy, is the main cause of

61 increased perinatal mortality among mothers and infants worldwide. The rate of PE in the United

62 States is approximately 3.4\% (Ghulmiyyah et al., 2012), and it is higher in developing countries

63 (Ananth et al., 2013). PE is marked by new-onset hypertension occurring after 20 weeks of

64 gestation, accompanied by either new-onset proteinuria or systemic multiple organ damage

65 (Committee on Practice Bulletins-Obstetrics, 2019). Severe PE may lead to convulsions, coma,

66 cerebral hemorrhage, heart failure, placental abruption, disseminated intravascular coagulation,

67 and even death (Bibbins-Domingo et al., 2017). Fetal delivery is the most effective treatment for

68 PE, with other treatments of relieving symptoms used only as an attempt to gain time for

69 enabling further maturity of the fetus. As a result, PE is the leading cause of premature birth and

70 low birth weight, especially severe PE (Ananth et al., 2006).

71

72 The exact pathogenesis of PE remains unclear. However, PE is considered a placenta-derived

73 disease because the syndrome resolves once the placenta is removed. There are two subtypes of

74 PE: early- and late-onset preeclampsia. Their pathogeneses are not identical. Early-onset

75 preeclampsia (EOPE) has a higher degree of placental damage, whereas late-onset preeclampsia

76 (LOPE) may focus on the interaction between the normal senescence of the placenta and a

77 maternal genetic susceptibility to cardiovascular and metabolic disease (Burton et al., 2019).

78 However, pathophysiological changes of the placenta further lead to endothelial dysfunction and

79 systemic inflammatory response, which are their common pathogenesis link. (Young et al., 80 2010). 
82 The placenta is in direct contact with the maternal circulation. Therefore, any changes in the 83 protein expression of placental tissue are reflected in maternal serum proteins (Norwitz, 2007). If

84 the types and levels of differentially expressed proteins (DEPs) in the serum of patients with PE

85 can be researched quantitatively and holistically, specific serum biomarkers may be found for 86 predicting PE and for further study of its pathogenesis. Compared with other proteomics

87 methods, isobaric tags for relative and absolute quantitation (iTRAQ) combined with liquid 88 chromatography-tandem mass spectrometry (LC-MS/MS) is considered more effective for

89 searching for serum or plasma biomarkers (Moulder et al., 2018). Therefore, in the present study, 90 we used iTRAQ and LC-MS/MS methods to identify serum proteins differentially expressed

91 between EOPE and LOPE and between women with PE and healthy pregnant women. We then

92 used bioinformatics analyses to determine the key proteins and related signaling pathways 93 associated with the development of EOPE and LOPE.

Materials \& Methods

Participants and clinical samples

97 The Medical Research Ethics Committee of Anhui Medical University reviewed and approved our research protocol and an informed patient consent form (Anhui Medical Ethics approval No. 20150192). All patients signed the approved written informed consent form prior to being 100 included in the study.

102 Blood samples were collected from December 2018 to May 2019 from 16 pregnant women, 8 of 103 whom had received a diagnosis of PE, and were in the Maternal and Child Health Hospital 104 Affiliated with Anhui Medical University. A PE diagnosis was made consistent with the 2019 
105 American College of Obstetricians and Gynecologists pregnancy hypertension guidance

106 (Committee on Practice Bulletins-Obstetrics, 2019). All included pregnant women were

107 primipara and without a disease that may have affected their serum protein levels, such as

108 infection, multiple pregnancy, or gestational diabetes mellitus. Four serum samples were

109 obtained from and allocated to each of the following four groups: EOPE, the EOPE control,

110 LOPE, and the LOPE control groups.

111

112 Protein extraction and quality testing

113 High-abundance proteins were removed from the serum samples using Pierce Top 12 Abundant

114 Protein Depletion Spin Columns (Thermo Fisher). The protein concentration was determined by

115 the Bradford method. Sodium dodecyl sulfate polyacrylamide gel electrophoresis (SDS-PAGE)

116 was performed to separate the proteins and evaluate the quality of samples.

Trypsin enzymatic hydrolysis and peptide iTRAQ isobaric labeling

119 After protein quantification, a centrifuge tube containing $60 \mu \mathrm{g}$ of protein solution was mixed

120 with $5 \mu \mathrm{L} 1 \mathrm{M}$ dithiothreitol at $37^{\circ} \mathrm{C}$ for $1 \mathrm{~h}$. Then $20 \mu \mathrm{L}$ of $1 \mathrm{M}$ iodoacetamide was added and

121 the solution allowed to react for $1 \mathrm{~h}$ at room temperature. All samples were pipetted into

122 ultrafiltration tubes, and the filtrate was discarded after centrifugation. UA buffer ( $8 \mathrm{M}$ urea, 100

$123 \mathrm{mM}$ Tris- $\mathrm{HCl}, \mathrm{pH} 8.0,100 \mu \mathrm{L}$ ) was added and the sample centrifuged at 14,000 $\mathrm{g}$ for $10 \mathrm{~min}$;

124 this step was repeated twice. Then, $50 \mathrm{mM} \mathrm{NH}_{4} \mathrm{HCO}_{3}(50 \mu \mathrm{L})$ was added and the filtrate

125 discarded after centrifugation; this step was repeated three times. Trypsin buffer $(40 \mu \mathrm{L})$ was

126 added and mixed, and the samples were centrifuged at $600 \mathrm{rpm}$ for $1 \mathrm{~min}$. The samples were then

127 subjected to enzymatic hydrolysis at $37^{\circ} \mathrm{C}$ for $12-18 \mathrm{~h}$. Transfer the enzymatic hydrolysate to a 
128 new centrifuge tube. After labeling with 8plex iTRAQ reagents multiplex kit, the same volume

129 of each sample was mixed together and desalted using a C18 cartridge.

130

$131 \quad$ LC-MS/MS analysis

132 The labeled samples were redissolved in $40 \mu \mathrm{L}$ of $0.1 \%$ formic acid aqueous solution. The 133 peptides were loaded onto a C18-reversed phase column $(3 \mu \mathrm{m} \mathrm{C} 18 \mathrm{resin}, 75 \mu \mathrm{m} \times 15 \mathrm{~cm})$. The 134 mobile phases consisted of $2 \%$ methyl cyanide $/ 0.1 \%$ formic acid $/ 98 \%$ water and $80 \%$ methyl 135 cyanide $/ 0.08 \%$ formic acid $/ 20 \%$ water. The gradient for the B phase increased linearly at $0-68$ $136 \mathrm{~min}$ from $7 \%$ to $36 \%$ and at $68-75 \mathrm{~min}$, from $36 \%$ to $100 \%$. Each sample was separated by 137 capillary high-performance liquid chromatography and was analyzed by an Orbitrap Fusion 138 Lumos mass spectrometer (Thermo Science). After the data were collected, they were processed 139 according to the flowchart shown in Fig. 1. Protein identification and quantification were done

140 by using the ProteinPilot Software, version 4.2 (Sciex). Human proteome databases containing 141 UniProt sequences were used to perform peptide identification. Serum proteins with fold changes 142 in their levels compared with control groups of at least 1.2 (in two of two replicates) and that 143 were also statistically significantly different between the groups at $P<0.05$ were further 144 analyzed.

Gene ontology (GO) and Kyoto Encyclopedia of Genes and Genomes (KEGG) signaling 147 pathway analyses

148 Metascape, a web-based resource (http://metascape.org) for gene and protein annotation, 149 visualization, and integration discovery (Fang et al., 2019; Soonthornvacharin et al., 2017) was 150 used to perform GO analyses. The KOBAS online analysis database 
151 (http://kobas.cbi.pku.edu.cn/) was used to performed KEGG pathway analyses (Kanehisa et al.,

152 2000). A two-sided $P<0.05$ was regarded significantly different.

153

154 Enzyme linked immunosorbent assay (ELISA)

155 PSG9, the downregulated protein in the LOPE group, was verified by ELISA kit (specification 156 and catalogue number: 96T, OM626395). The experiment was performed according to the 157 manufacturer instructions. Blood samples were collected from women with LOPE or normal 158 pregnancies.

159

160 Statistical analysis

161 Two-tailed Mann-Whitney U test was performed with SigmaPlot software. Values are expressed 162 as means \pm SEM. A value of $P<0.05$ was considered statistically significant.

163

164 Results

165 Participants

166 The mean and standard deviation (SD) age of the patients in the EOPE group was $31.8 \pm 5.0$ 167 years, and they were at a mean (SD) gestation of $31.9 \pm 2.9$ weeks; the mean (SD) age of the 168 participants in the EOPE control group was $30.0 \pm 1.0$ years, with a mean (SD) gestation of 31.5 $169 \pm 1.4$ weeks. No significant difference was found in age $(P=0.57)$ or gestational weeks $(P=$ 170 0.84) between these two groups. The mean (SD) age of the patients in the LOPE group was 24.8 $171 \pm 1.5$ years, with $37.8 \pm 1.5$ weeks' gestation; the mean $(\mathrm{SD})$ age of the participants in the LOPE 172 control group was $27.0 \pm 1.3$ years, with a mean (SD) of $38.9 \pm 1.3$ weeks' gestation. No 
173 significant difference was found in age $(P=0.15)$ or gestation $(P=0.37)$ between these two 174 groups.

175

176

SDS-PAGE

177 The total proteins in the molecular weight range of 10-220 kDa from 16 samples were

178 effectively separated by SDS-PAGE. The proteins were not degraded, and the high-abundance 179 proteins were obtained (Fig. 2).

180

181

MS/MS spectrum analysis and Identification of DEPS

182

LC-MS/MS is a powerful tool for identifying proteins in serum samples. We identified 413 serum proteins in the EOPE and EOPE healthy control groups, of which 70 were significantly 184 and differentially expressed between the two groups, with 51 upregulated and 19 downregulated (Table 1, Fig. 3). We also identified 470 proteins in the LOPE and LOPE control groups, of which 24 proteins were significantly and differentially expressed between the two groups, with 10 upregulated and 14 downregulated (Table 2, Fig. 3). Clustergrams generated describing the expression of these DEPs indicated that the expression patterns between the patient EOPE or LOPE groups obviously differed from their control groups, but the two patient groups, EOPE and LOPE, clustered together (Fig. 3B and 3D).

\section{GO functional annotation and enrichment analysis}

193 GO analysis is an important method and tool in the field of bioinformatics. It includes three 194 categories: cellular component, molecular function, and biological process. GO functional 195 annotation analysis results show the number of DEPs under each item in the three categories. GO 
196 functional enrichment analysis provides significant GO functional terms associated with the

197 DEPs, that is, those biological functions significantly correlated with the DEP. In vivo, different

198 proteins interact to generate a biological behavior, and a pathway-based analysis helps to further

199 understand those biological functions. A significant pathway enrichment analysis can determine

200 the most important biochemical and metabolic pathways and signal transduction pathways

201 associated with the DEPs.

202 The GO functional annotation analysis results for the EOPE group are shown in Fig. 4. For the

203 biological process category, the highest percentages of the proteins were associated with the term

204 biological regulation $(\mathrm{n}=43$ proteins; with the top 3 upregulated proteins in this process being

205 CHL1, LRP1, and CNTN1). For the cellular component category, the highest percentages of the

206 proteins were associated with the term extracellular region $(n=49$ proteins; with the top 2

207 upregulated proteins in this process being MMP2 and CHL1). For the molecular function

208 category, the highest percentages of the proteins were associated with the term binding $(\mathrm{n}=45$

209 proteins; with the top 3 upregulated proteins in this process being MMP2, CHL1, and PEPD).

210 For the LOPE group vs. their controls, the highest percentages of the proteins in the biological

211 process category were associated with the term biological regulation $(\mathrm{n}=17$; with the top 3

212 upregulated proteins in this process being PAPPA2, F7, and vWF). The highest percentages of

213 the proteins in the cellular component category were associated with term extracellular region (n

$214=18$; with the top 3 upregulated proteins in this process being PAPPA2, CETP, and F7). The

215 highest percentages of the proteins in the molecular function category were associated with the

216 term binding $(\mathrm{n}=13$; with the top 3 upregulated proteins in this process being APPA2, CETP,

217 and F7). The terms in the GO functional enrichment analysis for the EOPE group vs. their

218 controls mainly included response to stress, defense response, and negative regulation of 
219 catalytic activity, whereas the terms in the GO functional enrichment analysis for the LOPE

220 group vs. their controls included enzyme inhibitor activity and serine-type endopeptidase

221 inhibitor activity (Fig. 5).

222

223

KEGG signaling pathway analysis

224 The KOBAS online analysis tool was used to identify the functions associated with the DEPs 225 and the KEGG signaling pathways. Results of the KEGG pathway enrichment analysis showed 226 that complement and coagulation cascades, proteoglycans in cancer, and metabolic pathways 227 were the main signaling pathways associated with the EOPE group, whereas complement and 228 coagulation cascades were the main signaling pathways associated with the LOPE group (Fig. 6).

229 Thus, the results indicated that a functional change in coagulation was the main finding for both 230 EOPE and LOPE.

231

PSG9 protein level in serum

233 Serum level of PSG9 was measured by ELISA. The data showed a significant difference

234 between LOPE group and control group (4.54 \pm 1.22 vs. $6.32 \pm 1.73$, Fig. 7$)$. The result is 235 consistent with the study of mass spectrometry.

236

\section{Discussion}

238 Proteomics methods have provided some important information regarding PE. For example,

239 Blumenstein et al. (2009) used a differential in gel electrophoresis-based approach to identify

240 changes in the plasma proteome of pregnant women who subsequently developed PE. They

241 found that those DEPs are mainly involved in lipoprotein metabolism, the blood coagulation 
242 system, and the complement system. The results of the present study were consistent with those

243 of Blumenstein et al. (2009), but we also made some new discoveries (discussed below). These

244 results suggest that the pathogenesis of PE is complex and is associated with multiple proteins

245 and signaling pathways.

246

247 To maintain pregnancy and fetal growth progress within normal reference ranges, healthy 248 pregnant women develop physiological hyperlipidemia. However, they do not experience 249 angiopathy because high-density lipoprotein (a vascular protection factor) and low-density 250 lipoprotein (LDL, an atherogenic factor) also increase to protect the vascular endothelium from 251 injury (Jin et al., 2016; C Wang et al., 2017). Compared with healthy pregnant women, pregnant 252 women with PE display significantly increased serum triglycerides and LDLs, which may 253 enhance oxidative stress and ultimately lead to vascular endothelial cell injury (Huda et al., 2009; 254 Pohanka, 2013). Our study found that there were six DEPs associated with lipid regulation 255 increased in the PE groups, including ApoB, LRP1, ApoL3, ApoC-I, CETP, and ApoM. ApoB, the main carrier protein of LDL, is an atherogenic risk factor. Previous evidence supports that

257

258

259 260 261 262 263 ApoB is significantly upregulated in the plasma of patients with PE (Lin et al., 2019). CETP plays an important role in high-density lipoprotein metabolism and reverse cholesterol transport and is upregulated in the third trimester of pregnancy. Another study has reported that the TaqIB polymorphism of the CETP gene is significantly correlated with the triglyceride and total cholesterol levels in patients with severe PE (Belo et al., 2004). Here, we reported for the first time, to our knowledge, that LRP1, ApoC1, and ApoL3 are increased in the EOPE group. LRP1 and ApoC1 accelerate the development of atherosclerosis through different pathways (Mueller et al., 2018; Westerterp et al., 2007). Endothelial function decreases during PE, and endothelial 
265 dysfunction is a characteristic of atherosclerosis. ApoL3, as a regulator of MAPK and FAK 266 signaling in endothelial cells, has been shown to be involved in angiogenesis in vitro (Khalil et 267 al., 2018). Increased ApoL3 in PE may be a compensatory response to endothelial dysfunction. 268 Therefore, the current evidence suggests that dyslipidemia may be related to the development of 269 PE, but the specific pathogenesis remains to be explored in future studies.

270

271 Physiological hypercoagulability in healthy pregnant women can prevent intrapartum and 272 postpartum hemorrhage. However, abnormalities in coagulation, the anti-coagulation system, 273 and the fibrinolytic system lead to pathological hypercoagulability in PE (Dusse et al., 2011). In 274 the LOPE group of the present study, coagulation factors VII, vWF, and SRPIND1 were 275 upregulated group, whereas AAT and ATIII were downregulated compared with healthy 276 controls. In the EOPE group, coagulation factor V, plasminogen, and ADAMTS13 were 277 upregulated. These results are consistent with those of many previous trials (discussed below). 278 The level of plasma FVII in patients with severe PE is significantly higher than that in healthy 279 pregnant women; therefore plasma FVII levels may show high sensitivity and specificity in 280 differentiating between PE and normal pregnancy (Dusse et al., 2016). The coagulation factor 281 vWF is a specific marker that reflects damage of endothelial cells; thus, damaged microvascular 282 endothelial cells in PE promote the expression of vWF. Owing to the activation of the intrinsic 283 and exogenous coagulation pathways by damaged endothelial cells, a large number of 284 coagulation factors are activated. This leads to a massive generation of thrombin, which 285 antagonizes a large amount of anti-thrombin III, resulting in a significant decrease in its level 286 (Demir et al., 2010; Pottecher et al., 2009). In response to abnormalities in the coagulation 287 mechanism of PE, evidence-based medical study has also shown that oral administration of low- 
288 dose aspirin during early pregnancy can significantly reduce the incidence rate of PE (Rolnik et 289 al., 2017).

290

291 A growing number of studies have shown that abnormal expression with the complement system 292 is associated with PE (Agostinis et al., 2010; Derzsy et al., 2010). Our results support this 293 evidence, showing that expression levels of CFD, CIQC, CIRL, C9, C1S, and C1R were 294 significantly increased, while expression levels of C4B, FCN2, and FCN3 were significantly 295 decreased in the EOPE group compared with their control group. Moreover, the expression 296 levels of complement C1RL and C4B were decreased in the LOPE group compared with their 297 controls.

298

299 Downregulation of PSG1 and PSG9 expressed in the PE groups is an interesting finding in our 300 study. PSG is a pregnancy-specific glycoprotein that is synthesized and secreted into the blood 301 by placental syncytiotrophoblast cells. Rong et al. (2017) found that PSG9 significantly promotes 302 the angiogenesis of human umbilical vein endothelial cells. Chang et al. (2016) found a 303 significant increase in the number of cases with deletions in the PSG gene locus among patients 304 with PE. We hypothesize that downregulation of the PSG protein family may be involved in the 305 pathogenesis of PE by affecting the proliferation of endothelial cells although no specific 306 experimental evidence currently supports or disproves this hypothesis.

307

$308 \mathrm{PE}$ is considered a placenta-derived disease. In the classic two-stage model, placental stress leads 309 to dysfunction of maternal peripheral endothelial cells, systemic inflammatory response, and the 310 clinical syndrome of PE (Staff, 2019). This model is also reflected in our mass spectrometry 
311 results. In both the EOPE and LOPE groups, abnormalities of coagulation cascade activation,

312 lipid metabolism, and complement activation were found. However, the main stressor associated

313 with EOPE is placental hypoperfusion secondary to impaired spiral artery remodeling; by

314 contrast, in LOPE, the cause is more likely attributable to a mismatch between normal maternal

315 perfusion and the metabolic demands of the placenta and fetus (Burton et al., 2019). Spiral artery

316 remodeling is completed by the placental trophoblast cells continuously invading and destroying 317 the uterine spiral arterial wall and gradually replacing the endothelial cells. Many studies have 318 focused on the control of this invasion (Pollheimer et al., 2018; Wagner et al., 2011; Wu et al., 319 2016).

320

321 Unexpectedly, we also found 19 DEPs in the EOPE group that were closely related to placental 322 development or invasion of tumor cells. This result was not detected in the LOPE group, which 323 showed an increase only in PAPPA2, which affects the invasion and metastasis of placental 324 trophoblasts and leads to a gradual decline in placental function (Wagner et al., 2011). LYVE1, 325 CST3, and NCAM1 are also reportedly involved in placental vascular remodeling (Pawlak et al., 326 2019; G Song et al., 2010; XL Zhang et al., 2019). GRN, CD5L, ENO1, CHL1, CRISP3, VASN, 327 and TNIK promote the invasive ability of tumor cells (Aran et al., 2018; Bhandari et al., 2019; 328 Buhusi et al., 2003; Chon et al., 2016; Y Song et al., 2014; Voshtani et al., 2019; Y Wang et al., 329 2019). By contrast, SEMA4B, KRT1, KRT9, FBLN1, and PTGDS are involved in the anti330 invasive activity of tumor cells (Blanckaert et al., 2015; Jian et al., 2015; Marano et al., 2018; B 331 Zhang et al., 2018). MMP2 plays an important role in trophoblast invasion and is generally 332 thought to be downregulated in PE (Wu et al., 2016). We found the opposite result, that is, the 333 expression of MMP2 was upregulated in EOPE; however, expression of PI16, which inhibits 
334 MMP2 activity (Hazell et al., 2016), was also upregulated. PEPD is a hydrolase that affects

335 collagen biosynthesis, cell proliferation, and matrix remodeling. Pehlivan et al. (2017) have

336 shown that PEPD activity in the plasma, umbilical cord, and placental tissue of women with

337 pregnancy-induced hypertension is higher than that of healthy pregnant women. Our results also

338 indicated an upregulation of PEPD in the EOPE group. The dysregulation of the expression of

339 these proteins may be an important cause of placental dysfunction in EOPE.

340

341 Furthermore, previous studies have shown that soluble form of placenta-derived endoglin (sENG)

342 was upregulated in the serum of EOPE, which is involved in endothelial dysfunction in

343 coordination with soluble fms-like tyrosine kinase (Venkatesha et al., 2006). Our mass

344 spectrometry results were similar to that previous finding showing that endoglin was upregulated

345 in EOPE but not in LOPE group. This finding may also indicate more severe endothelial

346 dysfunction in EOPE.

347

\section{Conclusions}

349 In summary, the use of iTRAQ combined with LC-MS/MS was effective for screening serum for

350 DEPs in PE. We used bioinformatics to analyze the DEPs that showed significant changes in

351 their expression levels to provide potential indicators for detecting PE and ideas for the study of

352 pathogenesis in PE. In conclusion, the pathogenesis of EOPE and LOPE appeared to be related

353 to dysfunctions in coagulation cascade activation, lipid metabolism, and complement activation.

354 However, compared with that in LOPE, the pathogenesis of EOPE was associated with greater

355 placental injury. This study provides several new proteins in the serum which may potentially

356 have value in clinical diagnosis of EOPE and LOPE and offers potential mechanisms for the 
357 development of EOPE and LOPE, contributing to the future research on prediction, prevention, 358 and pathogenesis of PE.

359

360 Acknowledgments

361 This work was supported by the Anhui Province Science and Technology Innovation Project 362 Demonstration Project (No. 201707d08050003), and the Anhui Province Key Research and 363 Development Project (No. 201904a07020032).

364

365

\section{References}

366

367

368

369

370

371

372

373

374

375

376

377

378

379

380

381

Agostinis C, Bulla R, Tripodo C, Gismondi A, Stabile H, Bossi F, Guarnotta C, Garlanda C, De Seta F, Spessotto P, Santoni A, Ghebrehiwet B, Girardi G, and Tedesco F. 2010. An alternative role of $\mathrm{C} 1 \mathrm{q}$ in cell migration and tissue remodeling: contribution to trophoblast invasion and placental development. The Journal of Immunology. 185(7): 4420-4429.

Ananth CV, Keyes KM, and Wapner RJ. 2013. Pre-eclampsia rates in the United States, 19802010: age-period-cohort analysis. British Medical Journal. 347: f6564.

Ananth CV, and Vintzileos AM. 2006. Maternal-fetal conditions necessitating a medical intervention resulting in preterm birth. American Journal of Obstetrics and Gynecology. 195(6): 1557-1563.

Aran G, Sanjurjo L, Barcena C, Simon-Coma M, Tellez E, Vazquez-Vitali M, Garrido M, Guerra L, Diaz E, Ojanguren I, Elortza F, Planas R, Sala M, Armengol C, and Sarrias MR. 2018. CD5L is upregulated in hepatocellular carcinoma and promotes liver cancer cell proliferation and antiapoptotic responses by binding to HSPA5 (GRP78). FASEB Journal. 32(7): 3878-3891.

Belo LS, Gaffney D, Caslake M, Santos-Silva A, Pereira-Leite Ls, Quintanilha A, and Rebelo I. 2004. Apolipoprotein E and cholesteryl ester transfer protein polymorphisms in normal 
382

383

384

385

386

387

388

389

390

391

392

393

394

395

396

397

398

399

400

401

402

403

404

405

406

and preeclamptic pregnancies. European Journal of Obstetrics \& Gynecology and Reproductive Biology. 112(1): 9-15.

Bhandari A, Guan Y, Xia E, Huang Q, and Chen Y. 2019. VASN promotes YAP/TAZ and EMT pathway in thyroid carcinogenesis in vitro. American Journal of Translational Research. 11(6): 3589-3599.

Bibbins-Domingo K, Grossman DC, Curry SJ, Barry MJ, Davidson KW, Doubeni CA, Epling JW, Jr., Kemper AR, Krist AH, Kurth AE, Landefeld CS, Mangione CM, Phillips WR, Phipps MG, Silverstein M, Simon MA, and Tseng CW. 2017. Screening for Preeclampsia: US Preventive Services Task Force Recommendation Statement. The Journal of American Medical Association. 317(16): 1661-1667.

Blanckaert V, Kerviel V, Lepinay A, Joubert-Durigneux V, Hondermarck H, and Chenais B. 2015. Docosahexaenoic acid inhibits the invasion of MDA-MB-231 breast cancer cells through upregulation of cytokeratin-1. International Journal of Oncology. 46(6): 26492655.

Buhusi M, Midkiff BR, Gates AM, Richter M, Schachner M, and Maness PF. 2003. Close homolog of $L 1$ is an enhancer of integrin-mediated cell migration. Journal of Biological Chemistry. 278(27): 25024-25031.

Burton GJ, Redman CW, Roberts JM, and Moffett A. 2019. Pre-eclampsia: pathophysiology and clinical implications. British Medical Journal. 366: 12381.

Chon HJ, Lee Y, Bae KJ, Byun BJ, Kim SA, and Kim J. 2016. Traf2- and Nck-interacting kinase (TNIK) is involved in the anti-cancer mechanism of dovitinib in human multiple myeloma IM-9 cells. Amino Acids. 48(7): 1591-1599.

Committee on Practice Bulletins-Obstetrics. 2019. ACOG Practice Bulletin No. 202:

Gestational Hypertension and Preeclampsia. Obstetricians and Gynecologists. 133: e1e25. 
407 Demir C, and Dilek I. 2010. Natural coagulation inhibitors and active protein c resistance in $408 \quad$ preeclampsia. Clinics (Sao Paulo). 65(11): 1119-1122.

409 Derzsy Z, Prohaszka Z, Rigo J, Jr., Fust G, and Molvarec A. 2010. Activation of the complement 410 system in normal pregnancy and preeclampsia. Molecular Immunology. 47(7-8): 1500$411 \quad 1506$.

412 Dusse LM, Godoi LC, Gomes KB, Carvalho M, and Lwaleed BA. 2016. Tissue factor-dependent 413 pathway in severe preeclampsia revisited: a Brazilian cohort study. Blood Coagul $414 \quad$ Fibrinolysis. 27(4): 436-440.

415 Dusse LM, Rios DR, Pinheiro MB, Cooper AJ, and Lwaleed BA. 2011. Pre-eclampsia:

416 relationship between coagulation, fibrinolysis and inflammation. Clinica Chimica Acta.

417 412(1-2): 17-21.

418 Fang Y, Wang P, Xia L, Bai S, Shen Y, Li Q, Wang Y, Zhu J, Du J, and Shen B. 2019. Aberrantly hydroxymethylated differentially expressed genes and the associated protein pathways in osteoarthritis. PeerJ. 7: e6425.

421 Ghulmiyyah L, and Sibai B. 2012. Maternal mortality from preeclampsia/eclampsia. Semin 422 Perinatol. 36(1): 56-59.

423

424

425

426

427

428

429

430

431

432

Hazell GGJ, Peachey AMG, Teasdale JE, Sala-Newby GB, Angelini GD, Newby AC, and White SJ. 2016. PI16 is a shear stress and inflammation-regulated inhibitor of MMP2. Scientific Reports. 6(1).

Huda SS, Sattar N, and Freeman DJ. 2009. Lipoprotein metabolism and vascular complications in pregnancy. Clinical Lipidology. 4(1): 91-102.

Jian H, Zhao Y, Liu B, and Lu S. 2015. SEMA4B inhibits growth of non-small cell lung cancer in vitro and in vivo. Cellular Signalling. 27(6): 1208-1213.

Jin WY, Lin SL, Hou RL, Chen XY, Han T, Jin Y, Tang L, Zhu ZW, and Zhao ZY. 2016.

Associations between maternal lipid profile and pregnancy complications and perinatal outcomes: a population-based study from China. BMC Pregnancy Childbirth. 16: 60. 
433 Kanehisa M, and Goto S. 2000. KEGG: kyoto encyclopedia of genes and genomes. Nucleic $434 \quad$ Acids Res. 28(1): 27-30.

435 Khalil A, Poelvoorde P, Fayyad-Kazan M, Rousseau A, Nuyens V, Uzureau S, Biston P, El436 Makhour Y, Badran B, Van Antwerpen P, Boudjeltia KZ, and Vanhamme L. 2018. 437 Apoliporotein L3 interferes with endothelial tube formation via regulation of ERK1/2, FAK 438 and Akt signaling pathway. Atherosclerosis. 279: 73-87.

439 Lin N, Gu W, Hua RY, and Hou YY. 2019. Correlation between blood lipid levels in 440 earlypregnancy and preeclampsia. Journal of Shanghai University (Natural Science). 25(1): 18-23

442 Marano F, Zunino V, Frairia R, Arvat E, Castellano I, Bosco O, Catalano MG, and Fortunati N. 2018. Fibulin-1 interacts with Sex Hormone Binding Globulin and is linked to less aggressive estrogen-dependent breast cancers. Life Sciences. 207: 372-380.

Moulder R, Bhosale SD, Goodlett DR, and Lahesmaa R. 2018. Analysis of the plasma proteome using ITRAQ and TMT-based Isobaric labeling. Mass Spectrometry Reviews. 37(5): 583-

447 606.

Mueller PA, Zhu L, Tavori H, Huynh K, Giunzioni I, Stafford JM, Linton MF, and Fazio S. 2018. Deletion of Macrophage Low-Density Lipoprotein Receptor-Related Protein 1 (LRP1) Accelerates Atherosclerosis Regression and Increases CCR7 Expression in Plaque Macrophages. Circulation. 138(17): 1850-1863.

Norwitz E. 2007. Defective implantation and placentation laying the blueprint for pregnancy complications. Reproductive BioMedicine Online. 13(4): 591-599.

454 Pawlak JB, Balint L, Lim L, Ma W, Davis RB, Benyo Z, Soares MJ, Oliver G, Kahn ML, Jakus Z, and Caron KM. 2019. Lymphatic mimicry in maternal endothelial cells promotes placental spiral artery remodeling. Journal of Clinical Investigation: doi: 10.1172/JCI120446. 
458 Pohanka M. 2013. Role of oxidative stress in infectious diseases. A review. Folia Microbiol

459

460

461

462

463

464

465

466

467

468

469

470

471

472

473

474

475

476

477

478

479

480

481

482

483

(Praha). 58(6): 503-513.

Pollheimer J, Vondra S, Baltayeva J, Beristain AG, and Knofler M. 2018. Regulation of Placental Extravillous Trophoblasts by the Maternal Uterine Environment. Front Immunol. 9: 2597.

Pottecher J, Huet O, Degos V, Bonnet MP, Gaussem P, Duranteau J, Ozier Y, Mignon A, and Tsatsaris V. 2009. In vitro plasma-induced endothelial oxidative stress and circulating markers of endothelial dysfunction in preeclampsia: an observational study. Hypertens Pregnancy. 28(2): 212-223.

Rolnik DL, Wright D, Poon LC, O'Gorman N, Syngelaki A, de Paco Matallana C, Akolekar R, Cicero S, Janga D, Singh M, Molina FS, Persico N, Jani JC, Plasencia W, Papaioannou G, Tenenbaum-Gavish K, Meiri H, Gizurarson S, Maclagan K, and Nicolaides KH. 2017. Aspirin versus Placebo in Pregnancies at High Risk for Preterm Preeclampsia. New England Journal of Medicine. 377(7): 613-622.

Song G, Bailey DW, Dunlap KA, Burghardt RC, Spencer TE, Bazer FW, and Johnson GA. 2010. Cathepsin B, cathepsin L, and cystatin C in the porcine uterus and placenta: potential roles in endometrial/placental remodeling and in fluid-phase transport of proteins secreted by uterine epithelia across placental areolae. Biology of Reproduction. 82(5): 854-864.

Song Y, Luo Q, Long H, Hu Z, Que T, Zhang X, Li Z, Wang G, Yi L, Liu Z, Fang W, and Qi S. 2014. Alpha-enolase as a potential cancer prognostic marker promotes cell growth, migration, and invasion in glioma. Molecular Cancer. 13: 65.

Soonthornvacharin S, Rodriguez-Frandsen A, Zhou Y, Galvez F, Huffmaster NJ, Tripathi S, Balasubramaniam VR, Inoue A, de Castro E, Moulton H, Stein DA, Sanchez-Aparicio MT, De Jesus PD, Nguyen Q, Konig R, Krogan NJ, Garcia-Sastre A, Yoh SM, and Chanda SK. 2017. Systems-based analysis of RIG-I-dependent signalling identifies KHSRP as an inhibitor of RIG-I receptor activation. Nat Microbiol. 2: 17022. 
484 Staff AC. 2019. The two-stage placental model of preeclampsia: An update. Journal of 485 Reproductive Immunology. 134-135: 1-10.

486 Venkatesha S, Toporsian M, Lam C, Hanai J, Mammoto T, Kim Y, Bdolah Y, Lim K, Yuan H, 487 Libermann T, Stillman I, Roberts D, D'Amore P, Epstein FH, Sellke F, Romero R, 488 Sukhatme V, Letarte M, and Karumanchi S. 2006. Soluble endoglin contributes to the $489 \quad$ pathogenesis of preeclampsia. Nature madicine. 12(6): 642-649.

490 Voshtani R, Song M, Wang H, Li X, Zhang W, Tavallaie MS, Yan W, Sun J, Wei F, and Ma X. 4912019 . Progranulin promotes melanoma progression by inhibiting natural killer cell recruitment to the tumor microenvironment. Cancer Letters. 465: 24-35.

493 Wagner PK, Otomo A, and Christians JK. 2011. Regulation of pregnancy-associated plasma 494 protein A2 (PAPPA2) in a human placental trophoblast cell line (BeWo). Reprod Biol Endocrinol. 9(1): 48.

Wang C, Zhu W, Wei Y, Su R, Feng H, Hadar E, Hod M, and Yang H. 2017. The associations 497 between early pregnancy lipid profiles and pregnancy outcomes. Journal of Perinatology. 37(2): 127-133.

499

500

501

502

503

504

505

506

507

508

Wang Y, Sheng N, Xie Y, Chen S, Lu J, Zhang Z, Shan Q, Wu D, Zheng G, Li M, Zheng Y, and Fan S. 2019. Low expression of CRISP3 predicts a favorable prognosis in patients with mammary carcinoma. Journal of Cellular Physiology. 234(8): 13629-13638.

Westerterp M, Berbee JF, Pires NM, van Mierlo GJ, Kleemann R, Romijn JA, Havekes LM, and Rensen PC. 2007. Apolipoprotein C-I is crucially involved in lipopolysaccharide-induced atherosclerosis development in apolipoprotein E-knockout mice. Circulation. 116(19): 2173-2181.

Wu D, Hong H, Huang X, Huang L, He Z, Fang Q, and Luo Y. 2016. CXCR2 is decreased in preeclamptic placentas and promotes human trophoblast invasion through the Akt signaling pathway. Placenta. 43: 17-25. 
509 Young BC, Levine RJ, and Karumanchi SA. 2010. Pathogenesis of preeclampsia. Annual $510 \quad$ Review of Phytopathology. 5: 173-192.

511 Zhang B, Bie Q, Wu P, Zhang J, You B, Shi H, Qian H, and Xu W. 2018. PGD2/PTGDR2

512 Signaling Restricts the Self-Renewal and Tumorigenesis of Gastric Cancer. Stem Cells.

$513 \quad 36(7): 990-1003$.

514 Zhang XL, Xu FX, and Han XY. 2019. siRNA-mediated NCAM1 gene silencing suppresses

515 oxidative stress in pre-eclampsia by inhibiting the p38MAPK signaling pathway. Journal

$516 \quad$ of Cellular Biochemistry. 120(11): 18608-18617.

517

518 


\section{Figure Legends}

520

521 Figure 1: Flowchart of the data analysis procedure.

522

523 Figure 2. Removal of high-abundance proteins. (A) Lane E is the original sample from the 524 early-onset preeclampsia (EOPE) group. Lane M contains markers. Lanes 1-4 are from serum 525 samples obtained from the EOPE group after removing the highly abundant proteins, whereas lanes 5-8 are from the EOPE control group after removing the highly abundant proteins. (B)

527 528 529 530 531

532

Figure 3. Differential protein expression. (A and C) Volcano plots with red dots on the righthand side indicating upregulation, green dots on the left-hand side indicating downregulation, and black dots indicating no significant change in protein expression levels based on the criteria of an absolute $\log _{10}$ fold change and $P<0.05$ between early-onset preeclampsia and its control group (A), and between late-onset preeclampsia and its control group (C). (B and D) Clustergram for the expression of the DEPs between early-onset preeclampsia and control (B) and between late-onset preeclampsia and control (D).

Figure 4. Gene ontology functional annotation. The upregulated and downregulated proteins in the three categories of biological process, cellular component, and molecular function in (A) 
542 the early-onset preeclampsia group vs. its control group and (B) the late-onset preeclampsia

543 group vs. its control group.

\section{4}

545 Figure 5: Gene ontology (GO) functional enrichment. Enriched GO terms for the upregulated 546 and downregulated proteins and the associated protein numbers in (A) early-onset preeclampsia

547 vs. its control and (B) late-onset preeclampsia vs. its control.

548

549 Figure 6. Kyoto Encyclopedia of Genes and Genomes (KEGG) pathway enrichment. KEGG

550 pathways enriched for the upregulated and downregulated proteins and the associated protein 551 numbers in (A) early-onset preeclampsia vs. its control and (B) late-onset preeclampsia vs. its 552 control.

553

554 Figure 7. Protein level of pregnancy-specific beta-1-glycoprotein 9 (PSG9) in serum.

555 Concentration of PSG9 in the patient serum in control and LOPE groups. Values are shown as 556 the mean \pm SEM $(\mathrm{n}=10) ;{ }^{*} P<0.05$ for Control vs. LOPE. 


\section{Table $\mathbf{1}$ (on next page)}

List of differentially expressed proteins in the early-onset preeclampsia group. 
1 Table 1: List of differentially expressed proteins in the early-onset preeclampsia group.

2

\begin{tabular}{|c|c|c|c|c|}
\hline Regulated type & $\begin{array}{l}\text { Protein } \\
\text { accession }\end{array}$ & $\begin{array}{l}\text { GENE } \\
\text { NAME }\end{array}$ & PROTEIN DESCRIPTION & FC \\
\hline $\mathbf{U P}$ & A0A024R6R4 & MMP2 & Matrix metallopeptidase 2 & 21.48 \\
\hline $\mathbf{U P}$ & A8K2X4 & - & cDNA FLJ75401 & 12.87 \\
\hline UP & $\mathrm{O} 00533$ & CHL1 & Neural cell adhesion molecule L1-like protein & 7.69 \\
\hline UP & $\mathrm{J} 3 \mathrm{~K} 000$ & PEPD & PEPD protein & 6.6 \\
\hline UP & A8K3I0 & - & cDNA FLJ78437 & 6.31 \\
\hline UP & Q6UXB8 & PI16 & Peptidase inhibitor 16 & 5.76 \\
\hline UP & Q07954 & LRP1 & Prolow-density lipoprotein receptor-related protein 1 & 4.82 \\
\hline UP & Q12860 & CNTN1 & Contactin-1 & 4.64 \\
\hline UP & V9HWB4 & HEL-S-89n & Epididymis secretory sperm binding protein Li 89n & 4.63 \\
\hline $\mathbf{U P}$ & P35527 & KRT9 & Keratin, type I cytoskeletal 9 & 4.51 \\
\hline UP & P14543 & NID1 & Nidogen-1 & 3.86 \\
\hline $\mathbf{U P}$ & O95236 & APOL3 & Apolipoprotein L3 & 3.4 \\
\hline UP & A6XNE2 & - & Complement factor D preproprotein & 3.34 \\
\hline UP & P41222 & PTGDS & Prostaglandin- $\mathrm{H} 2$ & 3.17 \\
\hline UP & V9H1C1 & - & Gelsolin exon 4 (Fragment) & 2.95 \\
\hline UP & Q9Y5Y7 & LYVE1 & Lymphatic vessel endothelial hyaluronic acid receptor 1 & 2.95 \\
\hline UP & Q13201 & MMRN1 & Multimerin-1 & 2.83 \\
\hline $\mathbf{U P}$ & B3KQF4 & - & cDNA FLJ90373 & 2.74 \\
\hline & & DKFZp686M & & \\
\hline $\mathbf{U P}$ & Q6MZL2 & 0562 & Uncharacterized protein DKFZp686M0562 (Fragment) & 2.71 \\
\hline $\mathbf{U P}$ & J3KPA1 & CRISP3 & Cysteine-rich secretory protein 3 & 2.65 \\
\hline UP & P01034 & CST3 & Cystatin-C & 2.64 \\
\hline $\mathbf{U P}$ & A0A0S2Z4F1 & EFEMP1 & EGF Containing Fibulin Extracellular Matrix Protein 1 & 2.62 \\
\hline UP & P23142 & FBLN1 & Fibulin-1 & 2.57 \\
\hline UP & A0A384N669 & - & Epididymis secretory sperm binding protein & 2.48 \\
\hline UP & J3KNB4 & CAMP & Cathelicidin antimicrobial peptide & 2.47 \\
\hline UP & B7Z544 & - & cDNA FLJ51742 & 2.43 \\
\hline UP & A8K061 & - & cDNA FLJ77880 & 2.42 \\
\hline UP & A0A087WV75 & NCAM1 & Neural cell adhesion molecule 1 & 2.37 \\
\hline UP & Q9NQ79 & CRTAC1 & Cartilage acidic protein 1 & 2.24 \\
\hline $\mathbf{U P}$ & B2RBW9 & - & cDNA, FLJ95746 & 2.23 \\
\hline UP & A0A024RAA7 & $\mathrm{C} 1 \mathrm{QC}$ & Adiponectin B & 2.15 \\
\hline $\mathbf{U P}$ & P16070 & $\mathrm{CD} 44$ & CD44 antigen & $\begin{array}{l}2.06 \\
2.01\end{array}$ \\
\hline UP & Q76LX8 & ADAMTS13 & Von Willebrand Factor-Cleaving Protease & 2.01 \\
\hline $\mathbf{U P}$ & Q6EMK4 & VASN & Vasorin & 2 \\
\hline
\end{tabular}




\begin{tabular}{|c|c|c|c|c|}
\hline $\mathbf{U P}$ & D6RE86 & $\mathrm{CP}$ & Ceruloplasmin (Fragment) & 1.88 \\
\hline UP & H6VRG1 & KRT1 & Keratin 1 & 1.87 \\
\hline UP & Q86U17 & SERPINA11 & Serpin A11 & 1.81 \\
\hline UP & Q9UKE5 & TNIK & TRAF2 and NCK-interacting protein kinase & 1.75 \\
\hline UP & P61626 & LYZ & Lysozyme C & 1.74 \\
\hline UP & P02743 & APCS & Serum amyloid P-component & 1.74 \\
\hline UP & Q16853 & AOC3 & Membrane primary amine oxidase & 1.73 \\
\hline UP & Q9NZP8 & C1RL & Complement $\mathrm{C} 1 \mathrm{r}$ subcomponent-like protein & 1.73 \\
\hline UP & A0A024R035 & C9 & Complement C9 & 1.71 \\
\hline UP & A0A0A0MRJ7 & F5 & Coagulation factor $\mathrm{V}$ & 1.66 \\
\hline UP & P09871 & C1S & Complement $\mathrm{C} 1 \mathrm{~s}$ subcomponent & 1.65 \\
\hline UP & Q6PIL8 & IGK@ & IGK@protein & 1.63 \\
\hline UP & P49908 & SELENOP & Selenoprotein $\mathrm{P}$ & 1.55 \\
\hline UP & P02654 & APOC1 & Apolipoprotein C-I & 1.55 \\
\hline UP & D3DRR6 & ITIH2 & Inter-alpha (Globulin) inhibitor $\mathrm{H} 2$ & 1.54 \\
\hline UP & B4DPQ0 & $\mathrm{C} 1 \mathrm{R}$ & Complement $\mathrm{C} 1 \mathrm{r}$ subcomponent & 1.52 \\
\hline UP & J3KNP4 & SEMA4B & Semaphorin-4B & 1.51 \\
\hline DOWN & Q6GMX6 & IGH@ & IGH@protein & 0.56 \\
\hline DOWN & A0A0X9TD47 & - & MS-D1 light chain variable region (Fragment) & 0.43 \\
\hline DOWN & Q9UNU2 & C4B & Complement protein C4B frameshift mutant (Fragment) & 0.43 \\
\hline DOWN & P01591 & JCHAIN & Immunoglobulin J chain & 0.34 \\
\hline DOWN & Q14213 & EBI3 & Interleukin-27 subunit beta & 0.34 \\
\hline DOWN & P28799 & GRN & Granulins & 0.33 \\
\hline DOWN & B2R7N9 & - & cDNA, FLJ93532 & 0.32 \\
\hline DOWN & P00709 & LALBA & Alpha-lactalbumin & 0.29 \\
\hline DOWN & G5E9F7 & PSG1 & Pregnancy specific beta-1-glycoprotein 1 & 0.25 \\
\hline DOWN & A0A1B0GUU9 & IGHM & Immunoglobulin heavy constant mu (Fragment) & 0.23 \\
\hline DOWN & A0A075B6R9 & IGKV2D-24 & Immunoglobulin kappa variable 2D-24 & 0.23 \\
\hline DOWN & O75636 & $\mathrm{FCN} 3$ & Ficolin-3 & 0.22 \\
\hline DOWN & O43866 & CD5L & CD5 antigen-like & 0.2 \\
\hline DOWN & P06733 & ENO1 & Alpha-enolase & 0.16 \\
\hline DOWN & P09172 & DBH & Dopamine beta-hydroxylase & 0.16 \\
\hline DOWN & Q15485 & $\mathrm{FCN} 2$ & Ficolin-2 & 0.13 \\
\hline DOWN & Q86TT1 & & Full-length cDNA clone CS0DD006YL02 of Neuroblastoma & 0.08 \\
\hline DOWN & P00739 & HPR & Haptoglobin-related protein & 0.06 \\
\hline DOWN & P00738 & HP & Haptoglobin & 0.01 \\
\hline
\end{tabular}


Table 2 (on next page)

List of differentially expressed proteins in the late-onset preeclampsia group. 
1 Table 2: List of differentially expressed proteins in the late-onset preeclampsia group.

2

\begin{tabular}{|c|c|c|c|c|}
\hline Regulated type & $\begin{array}{l}\text { Protein } \\
\text { accession }\end{array}$ & GENE NAME & PROTEIN DESCRIPTION & FC \\
\hline UP & Q9BXP8 & PAPPA2 & Pappalysin-2 & 5.27 \\
\hline $\mathbf{U P}$ & A0A0S2Z3F6 & CETP & Cholesteryl ester transfer protein plasma isoform 1 & 3.51 \\
\hline UP & P08709 & F7 & Coagulation factor VII & 2.8 \\
\hline $\mathbf{U P}$ & Q6NS95 & IGL@ & IGL@protein & 2.67 \\
\hline UP & P04275 & VWF & von Willebrand factor & 2.46 \\
\hline $\mathbf{U P}$ & C0JYY2 & APOB & Apolipoprotein B & 1.93 \\
\hline UP & A0A140VK24 & - & Testicular secretory protein $\mathrm{Li} 24$ protein 1 & 1.74 \\
\hline $\mathbf{U P}$ & P05546 & SERPIND1 & Heparin cofactor 2 & 1.52 \\
\hline UP & O95445 & APOM & Apolipoprotein M & 1.34 \\
\hline $\mathbf{U P}$ & P80108 & GPLD1 & Phosphatidylinositol-glycan-specific phospholipase D & 1.26 \\
\hline DOWN & P05543 & SERPINA7 & Thyroxine-binding globulin & 0.82 \\
\hline DOWN & Q9NZP8 & C1RL & Complement $\mathrm{C} 1 \mathrm{r}$ subcomponent-like protein & 0.63 \\
\hline DOWN & A8K2T7 & - & Receptor protein-tyrosine kinase & 0.61 \\
\hline DOWN & Q00887 & PSG9 & Pregnancy-specific beta-1-glycoprotein 9 & 0.6 \\
\hline DOWN & P07333 & CSF1R & Macrophage colony-stimulating factor 1 receptor & 0.56 \\
\hline DOWN & Q2L9S7 & AAT & Alpha-1-antitrypsin MBrescia variant receptor 1 & 0.53 \\
\hline DOWN & A0A2S0BDD1 & ATIII-R2 & Antithrombin III isoform & 0.49 \\
\hline DOWN & Q8WW79 & SELL & L-selectin & 0.48 \\
\hline DOWN & P40189 & IL6ST & Interleukin- 6 receptor subunit beta (Fragment) & 0.47 \\
\hline DOWN & $\mathrm{B} 2 \mathrm{R} 7 \mathrm{Y} 0$ & - & cDNA, FLJ93654 & 0.41 \\
\hline DOWN & Q12860 & CNTN1 & member 2 (SERPINB2) & 0.36 \\
\hline DOWN & Q8WWZ8 & OIT3 & Oncoprotein-induced transcript 3 protein & 0.31 \\
\hline DOWN & A0A140TA29 & C4B & Complement C4-B & 0.21 \\
\hline DOWN & B2R950 & - & cDNA, FLJ94213 & 0.18 \\
\hline
\end{tabular}

3

4 
Figure 1

Flowchart of the data analysis procedure

Flowchart of the data analysis procedure

\section{Protein}

Raw data

Sequence database search
$\mathrm{GO}$ analysis

Metascape
Functional analysis
KEGG pathway analysis

KOBAS 
Figure 2

Removal of high-abundance proteins

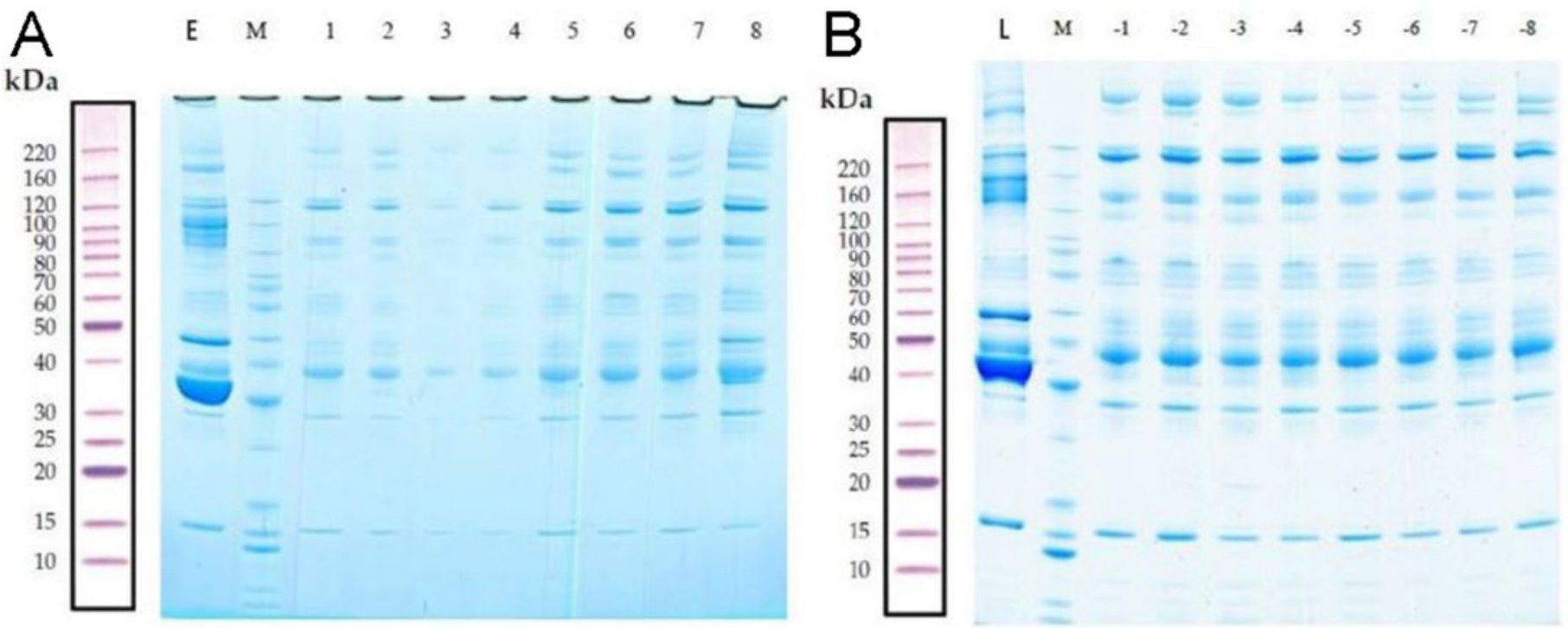


Figure 3

Differential protein expression a
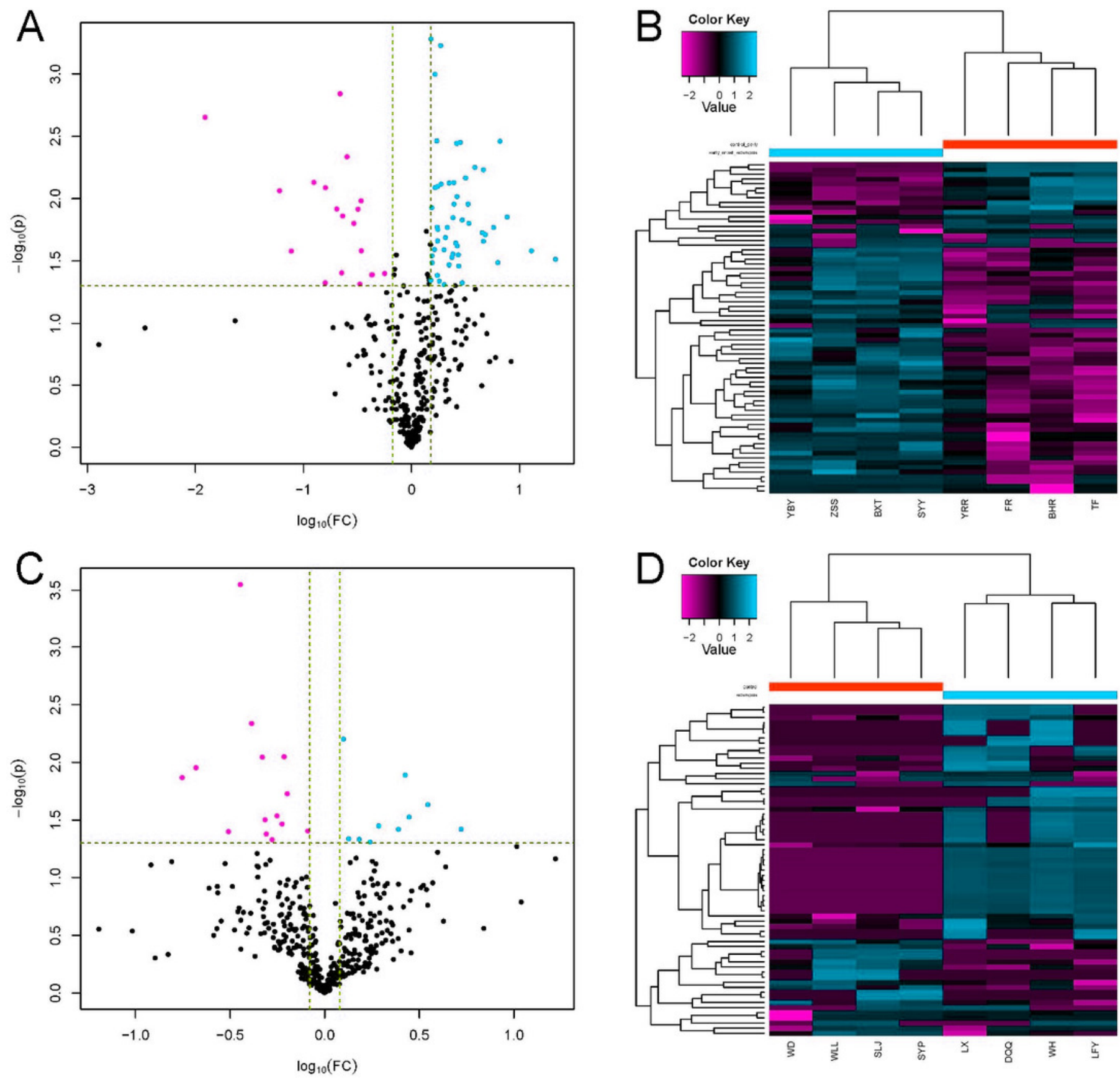
Figure 4

Gene ontology functional annotation

The upregulated and downregulated proteins in the three categories of biological process, cellular component, and molecular function in (A) the early-onset preeclampsia group vs. its control group and (B) the late-onset preeclampsia group vs. its control group. 

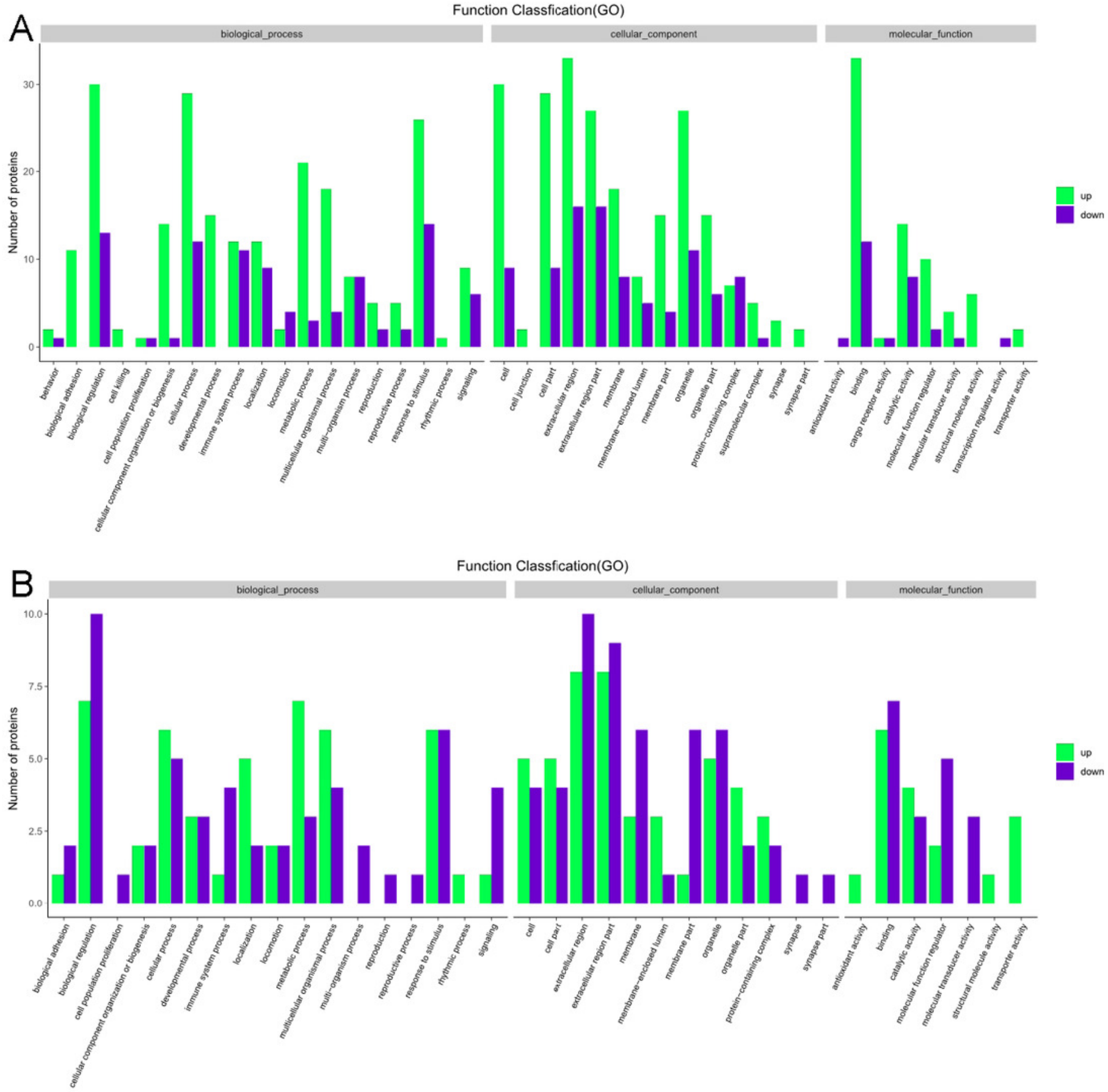
Figure 5

Gene ontology (GO) functional enrichment

Enriched GO terms for the upregulated and downregulated proteins and the associated protein numbers in (A) early-onset preeclampsia vs. its control and (B) late-onset preeclampsia vs. its control. 


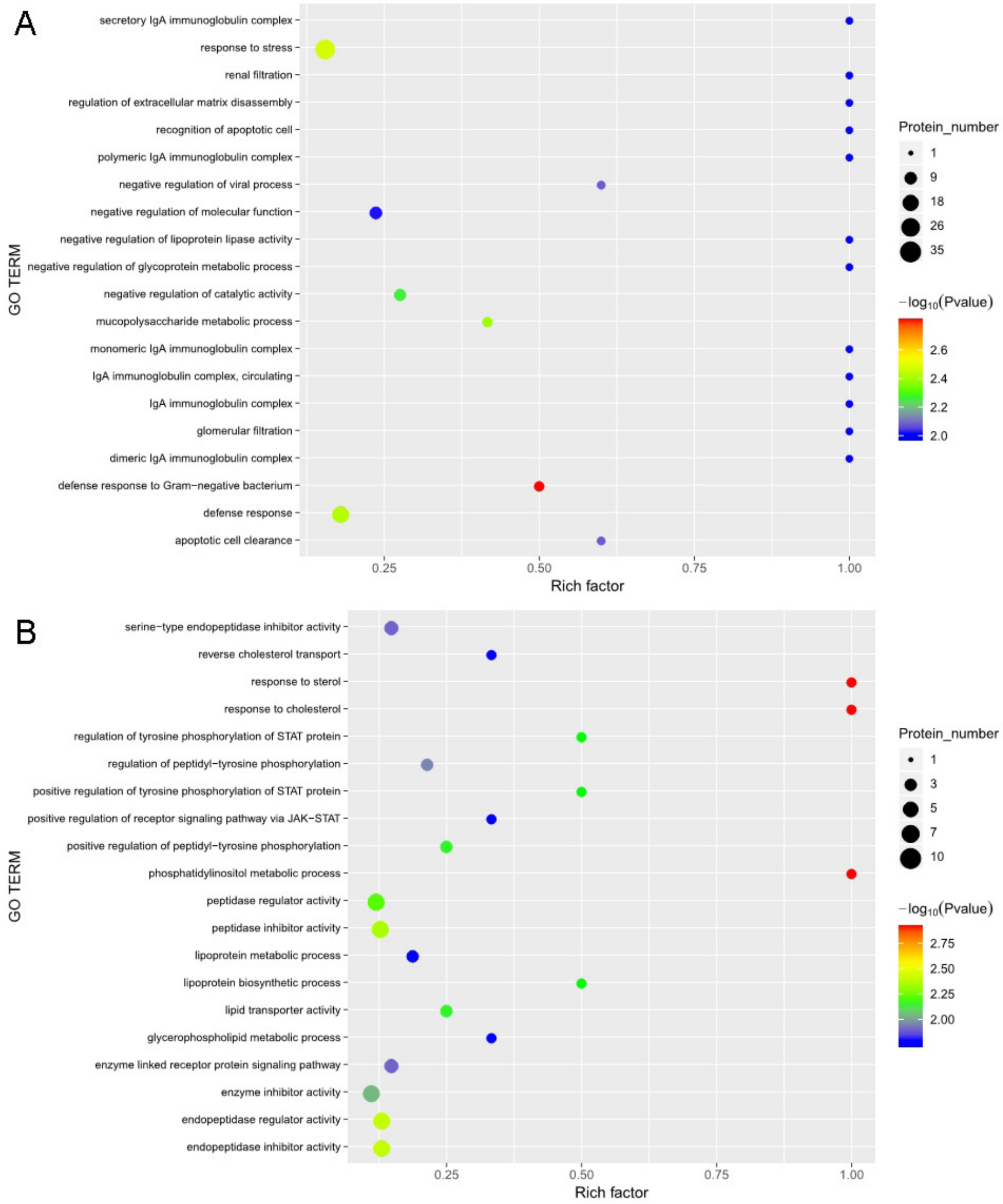


Figure 6

Kyoto Encyclopedia of Genes and Genomes (KEGG) pathway enrichment

KEGG pathways enriched for the upregulated and downregulated proteins and the associated protein numbers in (A) early-onset preeclampsia vs. its control and (B) late-onset preeclampsia vs. its control. 


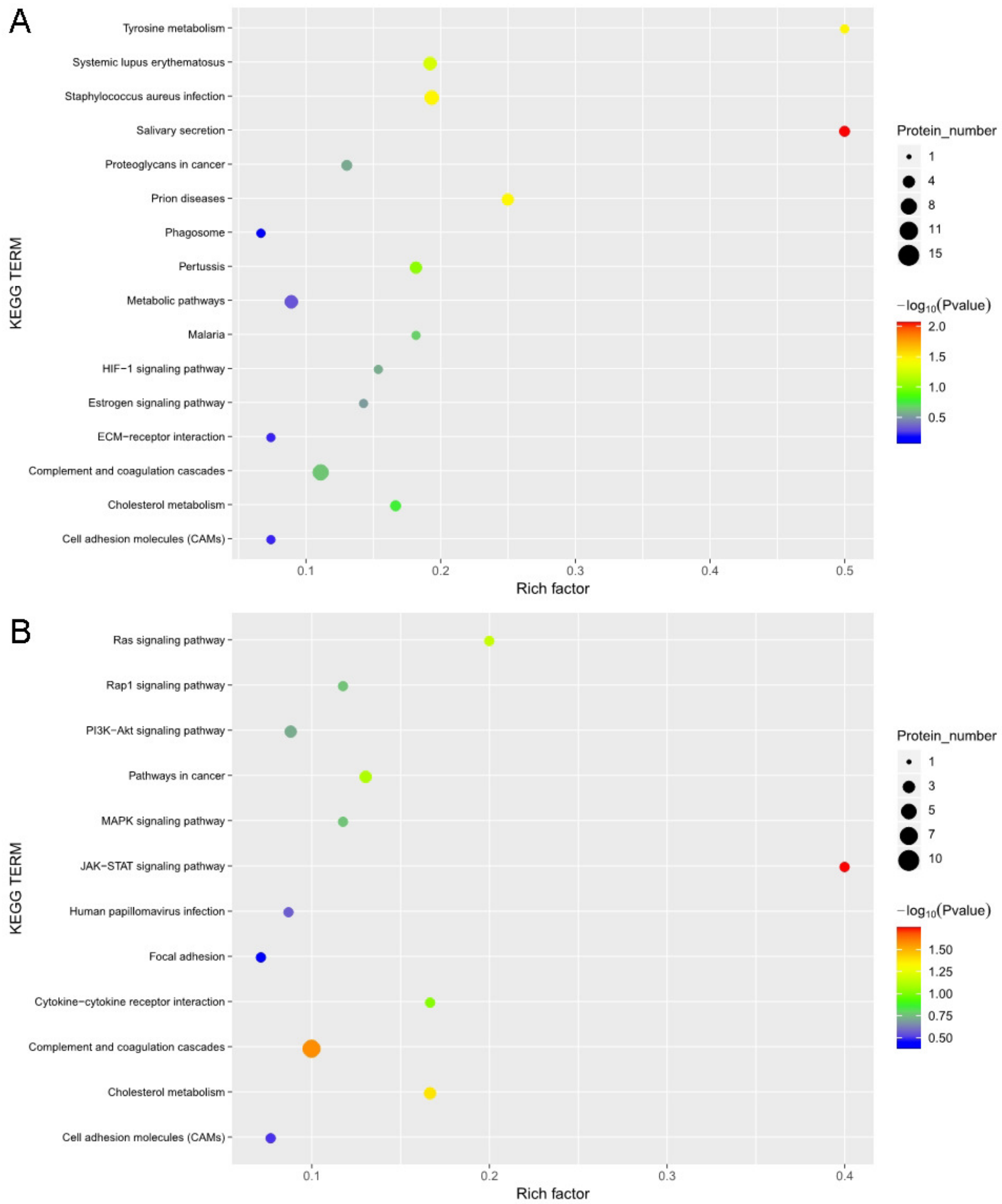


Figure 7

Protein level of pregnancy-specific beta-1-glycoprotein 9 (PSG9) in serum

Concentration of PSG9 in the patient serum in control and LOPE groups. Values are shown as the mean \pm SEM $(n=10) ; * P<0.05$ for Control vs. LOPE.

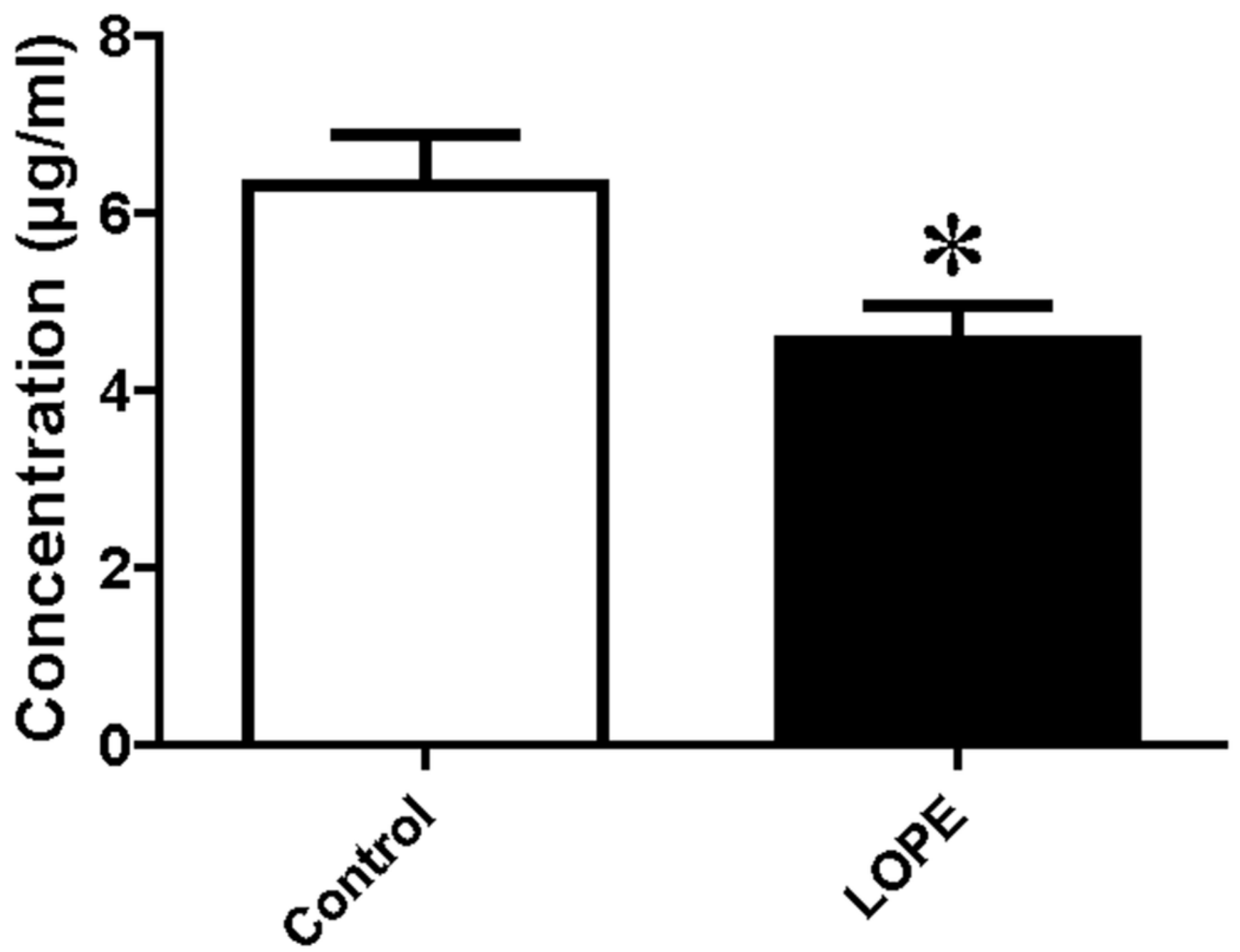

